\title{
Measuring User Satisfaction through Website Evaluation Framework
}

\author{
Umair Tahir and Arif Mushtaq
}

\begin{abstract}
Designing usable websites has become more important for usability experts due to the immense growth of the online community. Particularly, reaching the potential customers and retaining them for a longer period of time is one of the major challenges for website owners and web designers. Likewise, when a customer is adequately satisfied with his/her website interaction, the likelihood of his/her retention becomes higher too. Customer satisfaction is therefore one major criterion to measure the performance of a website. Researchers have given models to evaluate the overall performance of websites and one such evaluation framework is by Shanshan Qi. The said model has three aspects to evaluate the performance of a website: 1) Service Performance, 2) Technique Performance, and 3) Special Service to Disabled People. The Service Performance aspect of the model emphasizes on the parameters of customization, responsiveness, customer satisfaction, trust, and security. However, customer satisfaction can be measured with the help of certain metrics. And, these metrics are useful as an improvement factor for the website while making the design process iterative. In this paper, we have highlighted those metrics of customer satisfaction and we are presenting them as a model extension.
\end{abstract}

Index Terms-Website usability, website evaluation framework, measuring customer satisfaction.

\section{INTRODUCTION}

The popularity of Internet and the efficient use of Information Communication Technologies (ICTs) have motivated millions of businessmen to sell their products and services through websites [1]. People are obsessed to spend much of time over the Internet due to the invention of social networking websites, such as, Facebook and micro blogging twitter. In $2009^{1}$, "the global time spent by the users over the internet has increased by $82 \%$ than the year before" [2]. However, one needs to have a good website in order to sell or provide services online. Furthermore, to remain competitive in the internet world, it is necessary to adopt the latest web trends and web technologies while designing a website [3], [4]. Moreover, researchers [5] argued that "rapid diffusion of the Internet and open standard technologies is producing a significant growth of the demand of web sites and web applications with more and more strict requirements of usability." Therefore, making usable websites using the latest web trends and technologies is an important concern at

Manuscript received March 1, 2015; revised June 9, 2015.

The authors are with the Department of Graduate Studies and Applied Sciences, Islamabad, Pakistan (email: writetoumair@hotmail.com, mushtaq_arif@bahria.edu.pk).

${ }^{1}$ http://goo.gl/RoCZ7 present [1], [5].

Despite the technology enhancement factor, reaching the potential customers over the internet is also a major challenge [6]. Here, potential customer means that a customer who participates on a website; whereas, "customer participation is the degree to which a customer is involved in producing and delivering the service" [6]. On the other side, if a customer is not participating on a website, it means that a customer does not feel satisfied with the website [6]. It affects company's efforts in terms of time and money [7]. In addition, once a potential customer reaches the website, how to retain him/her for a longer period of time is another difficult job [8]. However, researchers [8] argued that customer retention involves fulfilling different aspects of satisfaction through a website. When a consumer feels satisfied with the online services, he/she would preferably stay loyal and would use the website again [9]. Furthermore, satisfaction is defined as "a website's communication ability in understanding consumers' needs" [10]. Hence, the loyalty of an online customer cannot be extended without considering the satisfaction. It has been proven that customers' satisfaction can be achieved by maintaining continuous interaction with them. Moreover, customers' feedback can be used to define their needs and hence websites designed, based on the needs defined by the customers themselves, will help to maintain their satisfaction [11]. Therefore, in this paper, we have proposed certain metric parameters, which can be used to evaluate and measure customer satisfaction of a website.

\section{LITERATURE REVIEW}

It is argued that there are no standards available to evaluate performance of a website. However, Shanshan [4] presented a framework for evaluating the overall performance of a website as shown in Fig. 1. The said framework is based on evaluating two types of performances. One is the technical performance, which is useful to evaluate the technical aspects (i.e. structure, usability, layout \& design, and effective navigation) of a website, and the other is service performance, used to evaluate the effectiveness of the service (i.e. customer satisfaction, trust, and response to customers). Furthermore, it highlights the key factors necessary to keep in mind while designing/developing a website. The proposed framework emphases on identifying detail problems based on three major aspects i.e. Usefulness, Service Quality and Website Physical Accessibility.

Usefulness symbolizes functionality and usability, which both are technical aspects of a website. Functionality refers to the contents of a website; and usability is treated as ease-of use [4]. Service Quality is the "extent to which a website 
facilitates effective shopping, purchasing, and delivery" [12]. Service Quality represents E-marketing strategies and reliability. E-marketing can be measured with the help of customization, responsiveness, and customer satisfaction. Whilst reliability can be measured with two sub-factors: trust and security. Physical Accessibility is based on W3C/WAI web content guidelines. Very few studies have been found in the literature on physical accessibility.

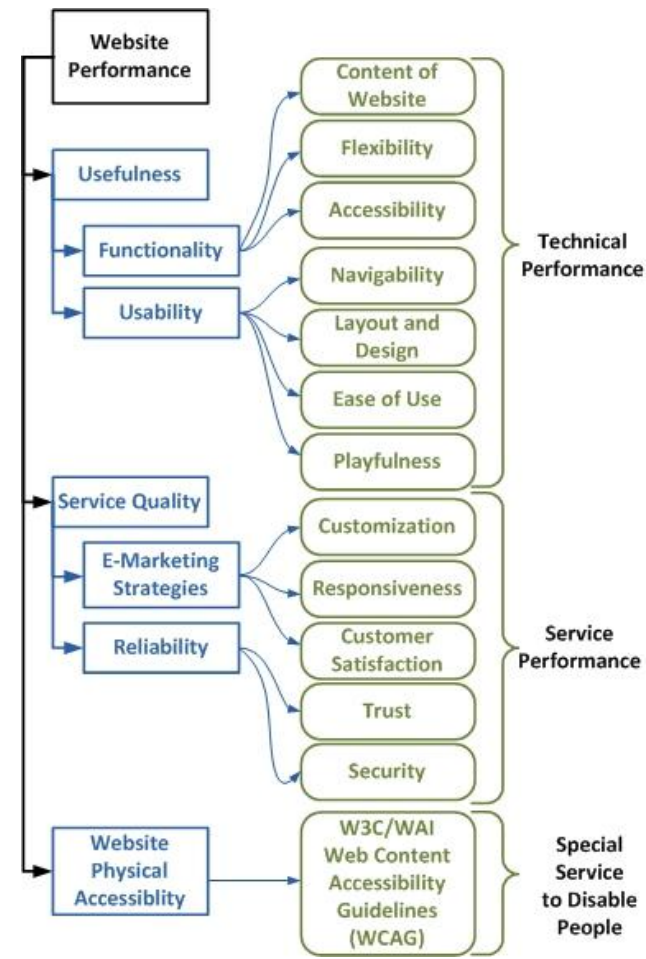

Fig. 1. A new framework on website evaluation by [4].

Literature defines Customization as how website attracts customers by addressing their preferences. Responsiveness is how easily a customer can contact the website's management and how efficiently the website responds [4], [13] and, Customer Satisfaction is website's communication ability in understanding consumers' needs [10]. Moreover, Trust signifies how fair the website is in terms of providing services and being loyal to customers. Whereas, security means how much a customer is protected while performing any task online, such as sharing personal information and making online payments [4], [13].

The evaluation framework given by Shanshan [4] has its foundation based on the theoretical concepts and is unable to measure the user satisfaction based on some key metrics. As there is no data available, so the facts cannot be derived and applied to improve upon the website's technical and service performance. Therefore, it is important to reconsider and extend the existing framework to measure the website performance effectively.

\section{PROPOSED WORK}

It is important to notice why new extensions are proposed? While designing a usable website, following attributes are important to be considered [14]:

- Structure - defines the information organization handled by the application and its relationships.
- Navigation - represents how information can be accessed.

- Presentation - describes how information is presented to the user.

The website structure, if not managed effectively, can affect the website's size, complexity, and page loading speed. In short, website's structure affects both the technical and service performance in the long run [15]. For this reason, it is important to measure how a website is performing. Therefore, the new extensions as shown in Fig. 2 would be able to measure the issues related to structure, navigation, and presentation of the website.

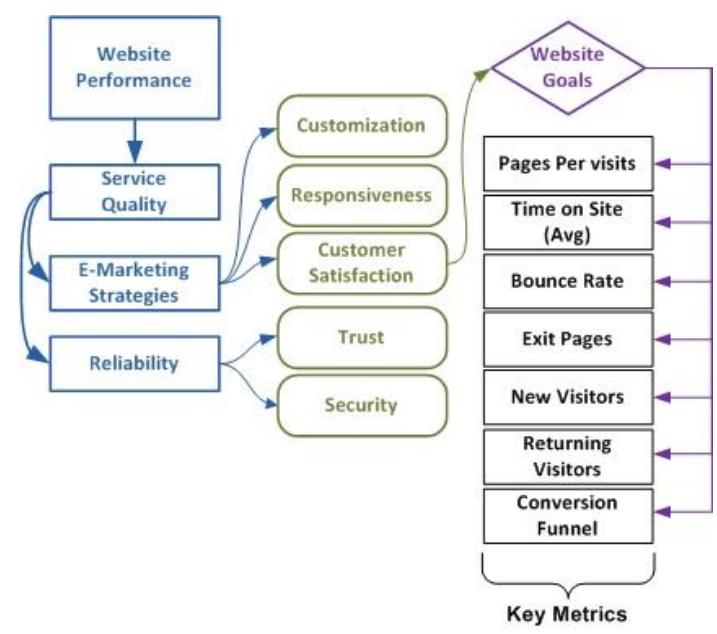

Fig. 2. Extended framework for measuring service performance of a website.

Google has provided web analytics tool, which is used for a website's evaluation by checking the required metrics for the website as discussed below [16]:

Pages Per visit - the average number of pages viewed per visit to the website, repeated views of a single page are counted in calculation.

Visit-Duration/Time-on-Site - average visit duration, calculated by dividing total time spent on site with number of sessions for the selected time frame.

Bounce Rate - is the percentage of bounced visits to the website. Visitor lands on a home page, looks around for a short period of time, and immediately leaves.

Exit Pages - identifies number of exits from website pages, compared with entrances.

New Visitors - when someone visits a website for the first time.

Returning Visitors - the visitor has browsed the website before.

Conversion Funnel - detailed overview of all the problematic areas of a website including the number of exits through inner pages.

Example Case: Goal-Purchasing Items from an Ecommerce Website - In order to better understand the usage of these metrics for any website, assume the specific goal: purchasing items from an ecommerce website. The following defined steps are performed by the visitors:

1) A person visits an ecommerce website.

2) That visitor starts putting an item into their shopping basket.

3) The visitor clicks "checkout".

4) The visitor enters shipping/ billing address and selects secure payment method. 
5) The Visitor enters all of his/her credit information and clicks "Buy".

Moreover, these five steps are as represented in Fig. 3.

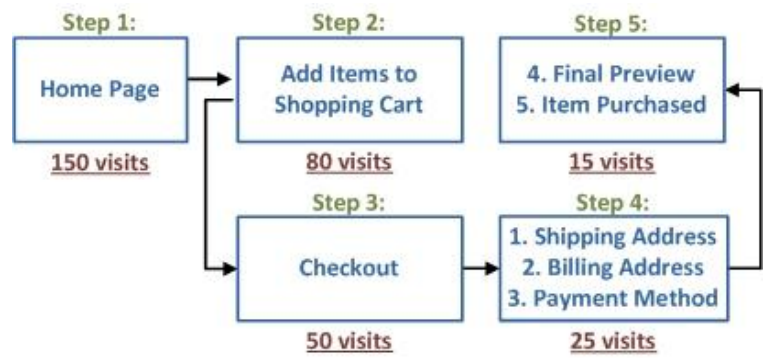

Fig. 3. Standard purchase process overview [17].

In order to get the better idea about the usage of proposed metrics, Table I explains about it in detail.

\begin{tabular}{|c|c|c|}
\hline & METRICS & EVALUATION \\
\hline 1 & $\begin{array}{l}\text { Pages Per } \\
\text { visit }\end{array}$ & $\begin{array}{l}\text { Usually product-ordering page of an ecommerce } \\
\text { website is about } 5 \text { layers deep as shown in Fig. } 3 \text {. } \\
\text { Checking "Pages per visit" can inform website } \\
\text { owners about the issues with the website pages if } \\
\text { visitors leave website in between the process. For } \\
\text { example, average } 2 / 3 \text { Pages per visit is probably a } \\
\text { bad sign for an ecommerce website. }\end{array}$ \\
\hline 2 & Exit Pages & $\begin{array}{l}\text { An exit page shows the unnatural exit points of a } \\
\text { website. } \\
\text { In order to check the "exit pages" of an ecommerce } \\
\text { website, if for example a large number of users are } \\
\text { dropping out at the second page of an ecommerce } \\
\text { shopping cart, then it may have a usability problem. } \\
\text { However, finding and fixing these problem points/ } \\
\text { exit pages can have a major impact on the bottom } \\
\text { line of a website. }\end{array}$ \\
\hline 3 & $\begin{array}{l}\text { New Visitors } \\
\text { Vs. } \\
\text { Returning } \\
\text { Visitors (\%) }\end{array}$ & $\begin{array}{l}\text { The difference of "New Visitors" vs. the "Returning } \\
\text { Visitors" can be checked for the ecommerce website. } \\
\text { For example, if from about } 3 \text { months, the new visitors } \\
\text { are about } 90 \% \text {, but the returning visitors are } 10 \% \text {, it } \\
\text { means the website is not capable to retain the old } \\
\text { visitors (returning visitors). The reasons may be the } \\
\text { website is not appealing to the visitors or may have } \\
\text { issues with its usability. }\end{array}$ \\
\hline 4 & Bounce Rate & $\begin{array}{l}\text { By checking the bounce rate of the website, one can } \\
\text { know the percentage for the total bounced visitors } \\
\text { from the website. In addition, what steps are needed } \\
\text { to take in order to reduce the website bounce rate? }\end{array}$ \\
\hline 5 & $\begin{array}{l}\text { Average time } \\
\text { on site }\end{array}$ & $\begin{array}{l}\text { Evaluating the metric "Average time on site" for an } \\
\text { ecommerce website does not have useful impact on } \\
\text { measuring customer satisfaction. Because of the } \\
\text { reason, lower time may indicate better customer } \\
\text { experience and smoother checkout. Also, if average } \\
\text { time on an ecommerce website is greater, it might be } \\
\text { possible that a website is difficult to navigate and to } \\
\text { find the product. But, this metric can be an effective } \\
\text { parameter for a blog website where higher average } \\
\text { time on site represents the good content on a site. }\end{array}$ \\
\hline
\end{tabular}

\section{DISCUSSION}

The evaluation framework given by author[s], behaves as a conceptual structure for building a website [4]. Conceptually service performance is based upon the technical performance. That is, if there is something wrong with the technical aspect of a website (e.g. navigation, design and layout), it may affect the service performance. This can be judged with the help of customer satisfaction attribute in the extended framework. It is also easy to judge the willingness of a returning customer by looking at the difference between "Returning and New Visitors'.

Furthermore, attaining customers' attention is the first important aspect for an online channel [4], [18]. Specifically, customer's satisfaction behavior (based on his/her attention) can be judged with the help of "Bounce Rate". It is also obvious that service performance can only be measured when the website is fully operational. It is then helpful to get the feedback of the user. With the help of user feedback, changes can be made to a website while making the design process iterative.

Moreover, judging customer satisfaction of a blog is different to an e-commerce website. 2 to 3 pages per visit are acceptable for a blog but not a good indication for an e-commerce website which requires at least 5-pages. However, exit page metric of extended framework could be helpful to check e-commerce web pages. Also, an attribute "Time on Site" is a good metric to judge satisfaction of a customer while he/she is reading the blog posts. After presenting the model extension, it has become possible now to measure the customer satisfaction aspect of the website performance to make the website design process iterative.

\section{CONCLUSION}

It is a well-known marketing prospect that recruits, a new customer is far more expensive than retaining an existing one [19]. Thus measuring the customer satisfaction (with the help of new extensions/metrics) will help retaining the customers on a website [15].

Measuring user satisfaction for a particular website is an important aspect of usability. If the data values about metrics, such as pages per visit, average duration of a user on the website, bounce rate, new vs. returning visitors are known, then it can be easy to predict the user behavior at a website. Thus, with these stats, not only user behavior can be predicted, but also the website design can be modified in multiple iterations. These stats can be observed on a regular basis for any website, which is helpful to stay updated about the user behavior. Therefore, the extended framework would help in building customer loyalty, encouraging repeated purchases, and maintaining long term relationships with customers.

\section{REFERENCES}

[1] F. Liu, "Usability evaluation on websites," presented at 9th International Conference on Computer-Aided Industrial Design and Conceptual Design, 2008.

[2] X. F. Wang, L. Tang, H. J. Gao, and H. Liu, "Discovering overlapping groups in social media," presented at IEEE International Conference on Data Mining, 2010.

[3] H. X. Li and R. Suomi, "Evaluating electronic service quality: A transaction process based evaluation method," presented at the European Conference on Information Management and Evaluation, September 2007.

[4] S. S. Qi, C. Ip, R. Leung, and R. Law, "A new framework on website evaluation," presented at 2010 International Conference on e-Business and e-Government (ICEE), 2010.

[5] P. S. Chang, I. H. Ting, and S. L. Wang, "Towards social recommendation system based on the data from microblogs," presented at International Conference on Advances in Social Networks Analysis and Mining, 2011.

[6] P. Dabholkar, "How to Improve perceived service quality by improving customer participation," Development in Marketing Science, NC: Academy of Marketing Science, pp. 483-487, 1990. 
[7] J. K. Shin, M. O. Oh, and M. Sook, "Effect of customer participation level on customers attributes, emotions, and behaviors in case of internet service failure," presented at Fifth International Joint Conference on INC, IMS and IDC, 2009.

[8] F. Reichheld and P. Shefter, "E-loyalty your secret weapon on the web," Harvard Business Review, vol. 78, no. 4, pp. 105-114, 2000.

[9] J. E. Collier and C. C. Bienstock, "Measuring service quality in e-retailing," Journal of Service Research, vol. 8, pp. 260-275, 2006.

[10] S. J. Barnes and R. T. Vidgen, "Data triangulation and web quality metrics: A case study in e-government," Information and Management, vol. 43, pp. 767-777, 2006.

[11] H. X. Zhang, "An e-commerce personalized recommendation system based on customer feedback," presented at 2011 International Conference Management and Service Science (MASS), 2011.

[12] V. A. Zeithaml, "Service quality, profitability, and the economic worth of customers: what we know and what we need to learn," Journal of the Academy of Marketing Science, vol. 28, pp. 67-85, 2000.

[13] J. P. C. Tong , V. G. Duffy , G. W. Cross, F. Tsung, and B. P. C. Yen, "Evaluating the industrial ergonomics of service quality for online recruitment websites," International Journal of Industrial Ergonomics, vol. 35, pp. 697-711, 2005.

[14] T. Conte, "Usability evaluation based on web design perspective," presented at First International Symposium on Empirical Software Engineering and Measurement, 2007.

[15] I. Alsmadi, A. T. Al-Taani, and N. A. Zaid, "Web structural metric evaluation," Developments in E-systems Engineering (DESE), 2010.

[16] Google Web Analytics Tool. (September 22, 2013) [Online]. Available: http://support.google.com/analytics/bin/answer.py?hl=en\&answer=10 06251
[17] Standard purchase process overview-ecommerce guide. [Online]. Available: http://devnet.kentico.com/docs/ecommerceguide/index.html?purchase _process_overview.htm

[18] C. Liao, P. Palvia, and H. N. Lin, "The roles of habit and web site quality in e-commerce," International Journal of Information Management, vol. 26, pp. 469-483, 2006.

[19] F. Cairncross, The Company of the Future: How the Communications Revolution Is Changing Management, Harvard Business Press, 01-Feb-2002.

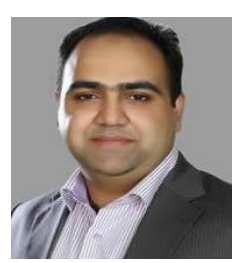

Umair Tahir was born in Pakistan on January 30 , 1987. He has done the bachelor of engineering in information technology in year 2008 specialized in software engineering. Further he had taken market experience in making web applications from 2008 to 2011. Then, he did his master of science in software engineering from Pakistan and done specialization in human computer interaction. At present, he is working as an internet marketing manager in a Dubai based firm eTek Studio. His interests are to make web and mobile applications usable and then bring traffic on those sites/applications and to inspect user behavior on those websites through different tools and methods. 